\title{
Effect of Cross Rolling on the Corrosion Resistance of AZ31 Magnesium Alloy
}

\author{
ZHIQUAN HUANG ${ }^{1,2}$, JINCHAO ZOU ${ }^{1,2 *}$, GUOWEI YANG ${ }^{1,2}$, YANCHUN ZHU ${ }^{1,2}$, \\ HONGYU LAI ${ }^{1,2}$, CHUANLU QI ${ }^{1,2}$ \\ ${ }^{1}$ Heavy Machinery Engineering Research Center of the Ministry of Education, Taiyuan University of Science and \\ Technology, Taiyuan, 030024 China \\ ${ }^{2}$ School of Mechanical Engineering, Taiyuan University of Technology, Taiyuan, 030024 China
}

\begin{abstract}
The effect of different rolling methods on the microstructure and corrosion behavior of AZ31 magnesium alloy in a $3.5 \% \mathrm{NaCl}$ solution was studied via potentiodynamic polarization scanning, constant current discharge and electrochemical impedance spectroscopy. Results show that the

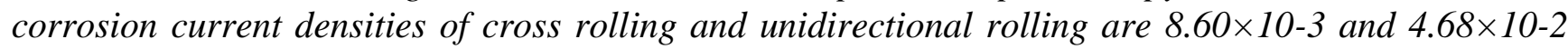
$\mathrm{A} / \mathrm{cm}^{2}$, respectively. Their difference is 5.4fold, the charge transfer resistance of cross rolling is large, the corrosion of one-way rolling is more serious than that of cross rolling, the discharge performance of cross rolling is more stable, and the anode polarization is small. After cross rolling, the grain size of the plate is relatively uniform and the corrosion products are non-adherent and less, so it is easy to fall off from its surface, which increases the effective contact between the electrolyte and the alloy surface and has more stable discharge performance.
\end{abstract}

Keywords: AZ31 magnesium alloy, rolling method, corrosion performance, metallographic structure

\section{Introduction}

The excessive density of traditional metal materials causes serious energy waste, which leads to the increase of greenhouse gas emissions and obvious global climate change. Magnesium and its alloys have been widely used in new energy vehicles, aerospace and other fields [1-3]. However, magnesium alloy has high self-activity, and is prone to self-corrosion, activation, passivation and other behaviors in humid environment, which seriously affects the stability and utilization of magnesium alloy [4-6]. Therefore, it is urgent to explore a processing method that can improve the corrosion resistance of magnesium alloy.

At present, the main methods of improving the corrosion resistance of magnesium alloys are alloying, surface modification, heat treatment, and plastic deformation [7-9]. The composite elements of $\mathrm{Nd}, \mathrm{Sm}$ and $\mathrm{Sr}$ change the proportion and shape of $\beta$-Li phase, subsequently reduce the current corrosion density, and improve the corrosion resistance of Mg-9Li-3Al magnesium alloy [10-12]. Song et al. [13] found that the surface of $\mathrm{Mg}-2 \mathrm{Zn}-\mathrm{Mn}-\mathrm{Ca}-\mathrm{Ce}$ magnesium alloy forms a dense magnesium hydroxide coating after it is simultaneously subjected to angular pressing and annealing, thereby enhancing corrosion resistance. After hot extrusion, the internal grains of AZ31 magnesium alloy are refined, and the disordered distribution of $\beta-\mathrm{Mg} 17 \mathrm{~A} 112$ becomes uniform. As a result, the corrosion resistance of AZ31 magnesium alloy significantly enhances [14]. However, alloying and surface modification are complex and expensive. By contrast, plastic deformation entails a low cost and is easy to implement, hence this method is the best choice for improving the electrochemical corrosion performance of magnesium alloy.

Rolling is one of the main methods of producing plates and strips. The grain size of cross rolling is more uniform and mostly equiaxed compared with those of unidirectional rolling, thereby greatly reducing the texture of the base surface and the anisotropy of materials. Thus, the performance becomes more uniform. In this study, the polarization curve, electrochemical impedance spectrum, and discharge performance of unidirectional and cross-rolled magnesium alloy plates were compared and analyzed by using the cast AZ31 magnesium alloy as our research object.

\footnotetext{
*email@institution.com
} 
The factors contributing to differences in properties were explored in terms of the microstructure and appearance of the samples after corrosion to provide a theoretical basis for improving the electrochemical properties of magnesium alloy plates.

\section{Materials and methods}

\subsection{Material preparation}

The rolling samples with dimensions of $100 \mathrm{~mm} \times 100 \mathrm{~mm} \times 4 \mathrm{~mm}$ were prepared from an AZ31 magnesium alloy ingot. The rolling experiments were carried out by double high rolling mill. Before rolling, the plate was heated to $400^{\circ} \mathrm{C}$ in a vacuum furnace and kept for $30 \mathrm{~min}$. The rolling path, including the rolling direction and the transverse direction, is shown in Figure 1. The specific rolling parameters were as follows: the rolling temperature was $400{ }^{\circ} \mathrm{C}$, the rolling speed was $0.1 \mathrm{~m} / \mathrm{s}$; the total reduction was $70 \%$, the reductions of each pass were $37.5 \%, 32 \%, 21 \%$, and $10 \%$,respectively; and the samples were returned to the furnace for $15 \mathrm{~min}$ between each pass to ensure that the rolling temperature is consistent with the set temperature. The samples were obtained in the middle of the two kinds of rolling plates. The sample name after unidirectional rolling was A, while that after cross rolling was B.

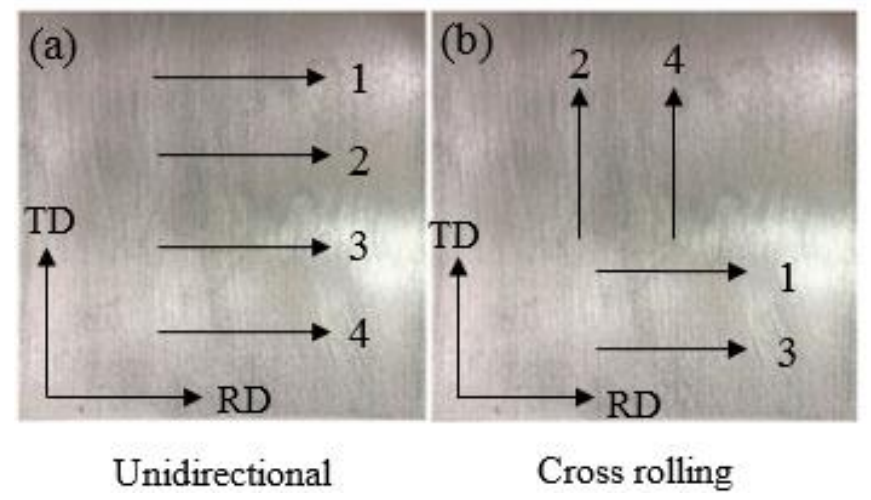

Figure 1. Schematic of rolling path

\subsection{Electrochemical test}

In this electrochemical test, the discharge area of the sample was $1 \mathrm{~cm}^{2}$, and the electrolyte used was $3.5 \mathrm{wt} \%$ sodium chloride solution. A three-electrode system was adopted in a PARSTAT 4000 electrochemical workstation, the saturated calomel electrode (SCE) was the reference electrode, the platinum plate was the auxiliary electrode, and the sample to be tested was the working electrode. The frequency range of the electrochemical impedance spectroscopy (EIS) test was $105 \mathrm{~Hz}$ to $1 \mathrm{~Hz}$, the AC disturbance voltage was $5 \mathrm{mV}$, and the test data were measured with ZSimpWin software. The scanning potential range of the potentiodynamic polarization test was $-0.3 \mathrm{~V}$ to $+0.4 \mathrm{~V}$, and the scanning rate was $3 \mathrm{mV} / \mathrm{s}$. Experimental data were fitted using CView software to obtain the corrosion potential, corrosion current density, corrosion rate, and other relevant parameters. The discharge current density of the constant current discharge test was $30 \mathrm{~mA} / \mathrm{cm}^{2}$, and the discharge duration was $1800 \mathrm{~s}$.

\subsection{Microscopic measurements}

For metallographic characterization, the AZ31 magnesium alloy samples after different rolling methods were polished step by step with 400\#, 600\#, 800\#, 1200\#, 1600\# sandpaper. The samples were washed with absolute ethanol and then polished by the polishing machine. The polished samples were eroded with the corrosive mixture of $5 \mathrm{~g}$ picric acid, $100 \mathrm{~mL}$ ethanol, $5 \mathrm{~mL}$ acetic acid and $10 \mathrm{~mL}$ distilled water, scanned with a metallographic microscope and SEM microscope (JSF-6700F) equipped with an energy-dispersive X-ray spectrometer (EDS; INCA, Oxford Instruments) to observe the grains, grain boundaries and intergranular precipitates of AZ31 magnesium alloy. 


\section{Results and discussions}

\subsection{Potentiodynamic polarization curve}

The potentiodynamic polarization curves of the AZ31 magnesium alloy in $3.5 \% \mathrm{NaCl}$ solution in different rolling methods are shown in Figure 2. In the figure, sample A is unidirectional rolling, and sample B is cross rolling.

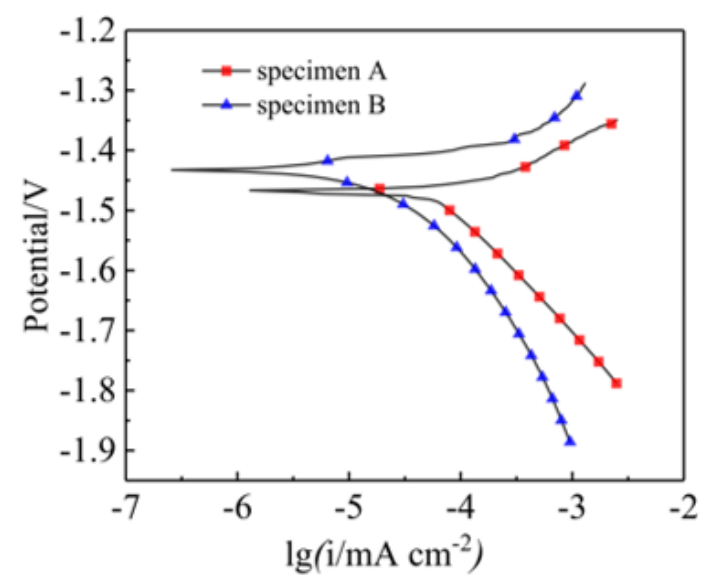

Figure 2. Potentiodynamic polarization curve of

AZ31 magnesium alloy in $\mathrm{NaCl}$ solution

Figure 2 shows that the two curves have a similar shape, indicating that they have the same electrochemical corrosion mechanism. Hydrogen evolution was carried out in the cathode polarization region, whereas the dissolution of magnesium was the main reaction in the anode polarization region. After Figure 2, At the beginning of the test, the gas is released on the surface of the magnesium alloy electrode: because of the hydrogen evolution of the cathode [15]. The corrosion potential Ecorr under the two modes slightly differs, whereas their self-corrosion current density remarkably varies. The corrosion current densities of cross rolling, and unidirectional rolling are $8.60 \times 10^{-3}$ and $4.68 \times 10^{-2}$ $\mathrm{A} / \mathrm{cm}^{2}$, respectively, with a difference of 5.4 fold. The corrosion current density is inversely proportional to the corrosion resistance of the material [16]. Table 1 also presents the values of corrosion rate C.R. expressed as penetration index. The difference of corrosion current density proves that cross rolling can improve the corrosion resistance of magnesium alloy plate better, furthermore, the self-corrosion in solution is reduced and the electrochemical performance is more stable.

Table 1. Electrochemical parameters obtained by potentiodynamic polarization curve fitting

\begin{tabular}{|c|c|c|}
\hline Specimen & $\mathrm{A}$ & $\mathrm{B}$ \\
\hline $\mathrm{E}_{\mathrm{corr}} / \mathbf{N}$ & -1.46 & -1.43 \\
\hline $\mathbf{I}_{\mathrm{corr}} / \mathbf{A ~ c m}^{-2}$ & $4.68 \times 10^{-2}$ & $8.60 \times 10^{-3}$ \\
\hline $\mathrm{CR} /(\mathbf{m m} /$ year $)$ & 1.79 & 0.33 \\
\hline
\end{tabular}

\subsection{Electrochemical impedance spectroscopy}
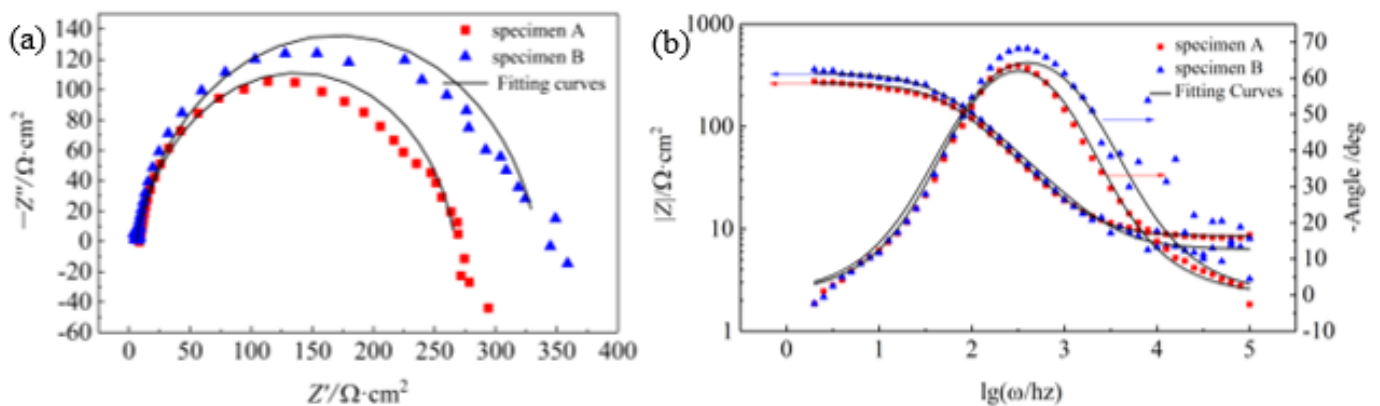

Figure 3. The electrochemical impedance spectrum: (a), Nyquist plot and (b), Bode plot 
Figure 3 shows the EIS curves of the AZ31 magnesium alloy in $3.5 \% \mathrm{NaCl}$ solution through two different rolling methods. After Figure 3, All Nyquist diagrams have only one high frequency impedance semicircle. The high-frequency capacitive arc is related to the double electric layer at the interface between the electrode and the solution, which represents the ability of electrons to pass through the double layer. The capacitive arc is not a perfect semicircle because of the frequency dispersion effect. Generally, the diameter of the semicircle can be approximately expressed as the charge transfer resistance [17]. According to the Nyquist diagram, the shape of impedance diagram under the two rolling methods is similar. The results show that the corrosion mechanism and the factors affecting the corrosion process are the same. As shown in Figure 3 (a), the high frequency capacitive arc radius of sample A after cross rolling is the smallest. The larger the arc radius is, the slower the corrosion rate and the better the corrosion resistance will be [18]. Therefore, the corrosion resistance of unidirectional rolled magnesium alloy plate is the worst. In addition, in the middle and low frequency region of 3 (b) Bode diagram, the impedance modulus of sample B is the largest, and the impedance modulus of the material in the low frequency region is inversely proportional to its electrochemical activity, while the electrochemical activity is inversely proportional to the corrosion resistance of the material [19]. Therefore, the corrosion resistance of the magnesium alloy plate after cross rolling is the best. As shown by the EIS results, cross rolling can better improve the corrosion resistance of the magnesium alloy material, this is consistent with the polarization curve.

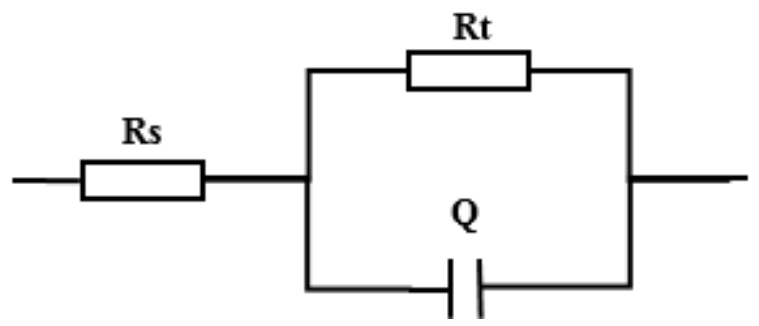

Figure 4. Equivalent circuit diagram

The electrochemical impedance spectrum in Figure 3 is fitted through ZSimpWin software to further analyze the corrosion mechanism. The equivalent circuit is shown in Figure 4, where Rs is the solution resistance, $\mathrm{Rt}$ is the charge transfer resistance, and $\mathrm{C}$ is the interface capacitance of the double electric layer between the electrode and the solution interface. The constant phase angle element $\mathrm{Q}$ is often used instead of the capacitance [20]. The fitting electrochemical parameters are shown in Table 2. The single rolling charge transfer resistance is $257.9 \Omega \cdot \mathrm{cm}^{2}$, and the cross-rolling charge transfer resistance is $328.2 \Omega \cdot \mathrm{cm}^{2}$. The charge transfer resistance of the material is inversely proportional to its corrosion rate [21], so cross rolling can improve the electrochemical performance of the magnesium alloy material better.

Table 2. Electrochemical parameters obtained by electrochemical impedance spectrum fitting

\begin{tabular}{|c|c|c|}
\hline Specimen & A & B \\
\hline $\mathbf{R s} / \mathbf{\Omega} \cdot \mathrm{cm}^{2}$ & 8.45 & 6.31 \\
\hline $\mathbf{R t} / \mathbf{\Omega} \cdot \mathbf{c m}^{2}$ & 257.9 & 328.2 \\
\hline $\mathbf{Q} / \mathbf{Q}^{-1} \cdot \mathbf{c m}^{2} \cdot \mathbf{s}^{\mathbf{n}}$ & $2.22 \times 10^{-5}$ & $2.25 \times 10^{-5}$ \\
\hline
\end{tabular}

\subsection{Constant current discharge}

Figure 5 shows the voltage-time curve of $30 \mathrm{mAcm}^{-2}$ constant current discharge of magnesium alloy in $3.5 \mathrm{wt} \%$ sodium chloride solution under different rolling modes. At the beginning of discharge, the discharge potential of the two samples shifts rapidly to more positive values with time due to the influence of the corrosion product magnesium hydroxide attached to its surface during the discharge process. The discharge potential stabilizes as discharge time is prolonged. The discharge potential of the material is related to its electrochemical activity. The more negative the discharge 
potential of the anode material is, the more active the electrochemical activity is [22]. The average discharge potential of sample A and sample B is $-2.23 \mathrm{~V}$ vs. SCE, The results show that the discharge capacity of the samples processed by two rolling methods is almost the same, but the constant current discharge of the sample after cross rolling is relatively stable as shown in curve B in Figure 5, while the constant current discharge of the unidirectional rolling has obvious attenuation trend, indicating that the magnesium alloy plate has more stable discharge capacity after cross rolling.

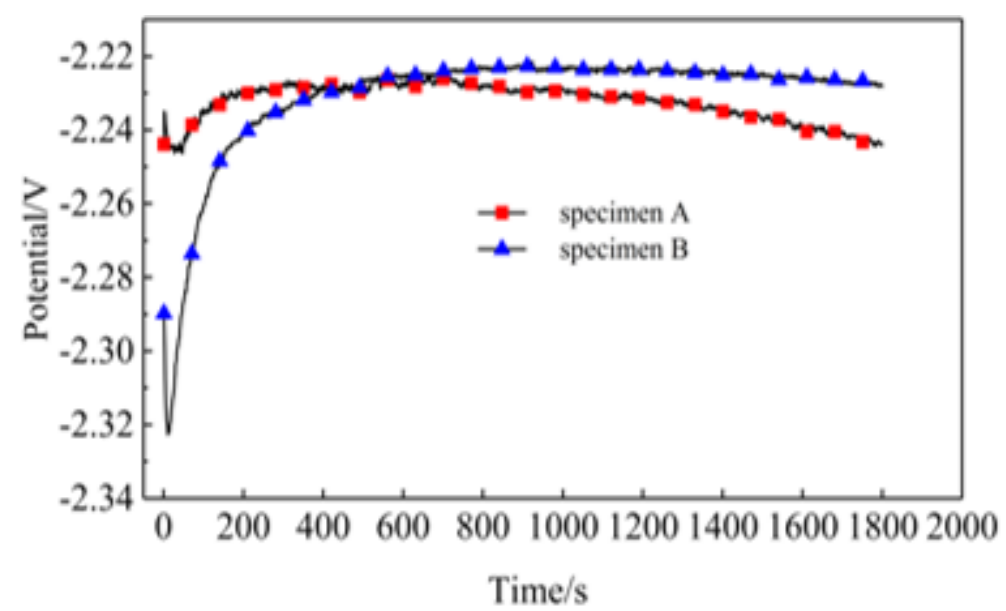

Figure 5. Constant current discharge curve

\subsection{Microstructure of the AZ31 magnesium alloy}

The metallographic structure and corrosion morphology of AZ31 magnesium alloy plate after rolling are shown in Figure 6. After unidirectional rolling and cross rolling, the metallographic structure is all mixed crystal distribution. The grain after unidirectional rolling is coarse, and the grain shape is mostly columnar crystal [23], with only a small amount of equiaxed crystal as shown in Figure 6 (a). There is obvious dynamic recrystallization during cross rolling, and there are finer recrystallized grains, so the grains are mostly equiaxed and there are only a few columnar grains as shown in Figure 6 (b). The electrochemical performance is related to the grain size and grain uniformity of the material [24]. After unidirectional rolling, the plate not only has large grain size and uneven distribution, but also has defects along the grain boundary. The plate with large grain size is easy to dissolve in the solution, which accelerates the corrosion of the matrix and reduces the discharge efficiency.

Observe the corrosion morphology of AZ31 magnesium alloy plate after rolling. After unidirectional rolling, the surface of sample a is attached by thick discharge products. As shown in Figure 6 (c), the corrosion products are mainly $\mathrm{MgO}$ or $\mathrm{Mg}(\mathrm{OH})_{2}$ oxide films, which are relatively dense in structure and are not easy to fall from the sample surface. During the discharge process, further contact between the substrate and the solution is prevented, resulting in a decrease in the effective area, a rapid positive potential shift, and serious self-corrosion. As shown in Figure 6 (d), the discharge products on the surface of sample B after cross rolling are less, and the oxidation products are easy to fall off from the surface during the discharge process. The magnesium matrix further reacts with the solution, and has more stable discharge performance. In addition, the surface of the alloy is relatively smooth, the corrosion products are loose, the anode polarization is reduced, and the utilization rate of magnesium alloy is increased [25]. Combined with the above discussion, the electrochemical properties of the cross rolled materials are better. 


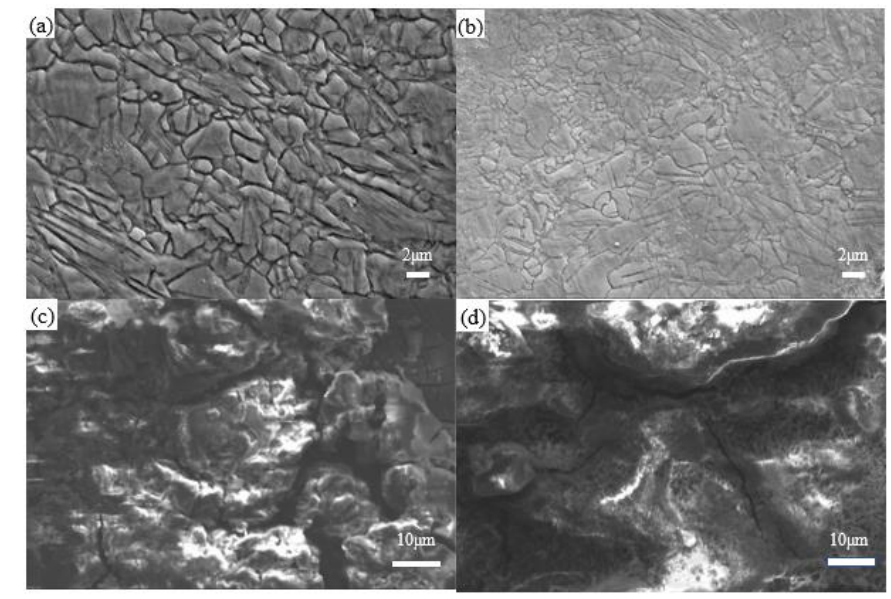

Figure 6. Microstructure and corrosion features under different rolling: (a), (c) unidirectional rolling (b), (d) cross rolling

\section{Conclusions}

1) The corrosion current densities of magnesium alloy after cross rolling and unidirectional rolling are $8.60 \times 10^{-3}$ and $4.68 \times 10^{-2} \mathrm{~A} / \mathrm{cm}^{2}$, respectively. The difference between them is 5.4fold. Cross rolling greatly improves the corrosion resistance of magnesium alloy. The constant current discharge curve of cross rolling is more stable, so its discharge capacity is relatively stable.

2) After cross rolling, the grain size of the plate and its performance are uniform, and its discharge products are less, so it is easy to fall off from its surface, which increases the effective contact between the electrolyte and the alloy surface and has more stable discharge performance. In addition, the surface of the alloy is relatively smooth, the corrosion products are loose, the anode polarization is reduced, and the utilization rate of magnesium alloy is increased.

Acknowledgements: This research was funded by the National Natural Science Foundation of China (51604181); the key Research Science and Technology Innovation of Shanxi Province (201803D121026); Shanxi Province Science and Technology Major Project (20181102016); and Shanxi Province Graduate Innovation Project (No. 2019SY478).

\section{References}

1. LU, D.Z., HUANG, Y. L., JIANG, Q. T., ZHENG, M., DUAN, J. Z., HOU, B. R., "An approach to fabricating protective coatings on a magnesium alloy utilising alumina", Surf. Coat. Tech, 367, no.15, 2019, p. 336.

2.WANG, Y. GU, Z.P., LIU, J., JIANG, J., YUAN, N.Y., PU, J. B., DING, J.N., “An organic/ inorganic composite multi-layer coating to improve the corrosion resistance of AZ31B Mg alloy", Surf. Coat. Tech, 360, no. 25, 2019, p. 276.

3. CAO, F.Y., SONG, G.L., ATRENS, A., "Corrosion and passivation of magnesium alloys", Corros. Sci., 111, 2016, p. 835.

4. LIAO, J.S., HOTTA, M., "Corrosion products of field-exposed Mg-Al series magnesium alloys", Corros. Sci., 112, 2016, p. 276.

5. MUHAFFEL, F., CIMENOGLU, H., "Development of corrosion and wear resistant micro-arc oxidation coating on a magnesium alloy", Surf. Coat. Tech, 357, no. 15, 2019, p. 822.

6. CHEN, X. B., BIRBILIS, N., ABBOTT, T. B., "Effect of [Ca2+] and [PO43-] levels on the formation of calcium phosphate conversion coatings on die-cast magnesium alloy AZ91D", Corros. Sci., 55, 2012, p. 226.

7. WANG, N.G., WANG, R.C., FENG, Y., XIONG, W.H., ZHANG, J.C., DENG, M., "Enhancement of the discharge performance of AP65 magnesium alloy anodes by hot extrusion", Corros. Sci., 81, 2014, p. 85.

8. SONG, X.J., SI, Y. J., LIU, J., LI, M. J., XIONG, Z. P., "Enhanced Corrosion Resistance of AZ91D Magnesium Alloy by Electric Field-Assisted Anodizing”, Int. J. Electrochem. Sci., 14, 2019, p. 8750. 
9. LIU, D., HUANG, J.C., ZHOU, Y., Ding, Y.G., "Enhanced Corrosion Resistance and Photocatalytic Properties of Bi2O3/Phosphate Composite Film Prepared on AZ91D Magnesium Alloy by Phosphating", Int. J. Electrochem. Sci., 14, 2019, p. 1434.

10. DINESH, P., MANIVANNAN, S., KUMARESH BABU, S.P., NATARAJAN, S., "Effect of Nd on the microstructure and corrosion behaviour of $\mathrm{Mg}-9 \mathrm{Li}-3 \mathrm{Al}$ magnesium alloy in $3.5 \mathrm{wt} . \% \mathrm{NaCl}$ solution", Materials Today: Proceedings, 15, no. 1, 2019, p. 126.

11. HU, Z., LIU, R. L., KAIRY, S. K., LI, X., YAN, H., BIRBILIS, N., "Effect of Sm additions on the microstructure and corrosion behavior of magnesium alloy AZ91", Corros. Sci., 149, no. 1, 2019, p. 144.

12. NIU, J. X., CHEN, Q. R., XU, N. X., WEI, Z. L., "Effect of combinative addition of strontium and rare earth elements on corrosion resistance of AZ91D magnesium alloy", Trans. Nonferrous Met. Soc. China, 18, no. 5, 2008, p. 1058.

13. SONG, D., LI, C., LIANG, N. N., YANG, F. L., JIANG, J. H., SUN, J. P., WU, G. S., MA, A. B., MA, X.L., "Simultaneously improving corrosion resistance and mechanical properties of a magnesium alloy via equal-channel angular pressing and post water annealing", Mater. Design, 166, no. 15, 2019, p. 107621.

14. ZHANG, Z. M., XU, H. Y., WANG, Q., "Corrosion and mechanical properties of hot-extruded AZ31 magnesium alloys", Trans. Nonferrous Met. Soc. China, 18, 2008, p. s140.

15. CAI, X., WEI, F. S., XU, X. L., ZHANG, Y., "Influence of magnesium content on structure and electrochemical properties of La1-xMgxNi1.75Co2.05 hydrogen storage alloys", J. Rare. Earth, 34, no. 12, 2016, p. 1235.

16. ZHU, Y.Y., GAO, W. D., HUANG, H.D., CHANG, W. H., ZHANG, S. F., ZHANG, R. F., ZHAO, R.F., ZHANG, Y.J., "Investigation of corrosion resistance and formation mechanism of calcium-containing coatings on AZ31B magnesium alloy, Appl. Surf. Sci.”, 487, no. 1, 2019, p. 581.

17. ZHENG, T. X., HU, Y. B., YANG, S. W., "Fabrication of corrosion-resistant superhydrophobic coating on magnesium alloy by one-step electrodeposition method”, J. Magnes. Alloy, 5, no. 2, 2019, p. 193.

18. LI, J. R., JIANG, Q. T., SUN, H. Y., LI, Y. T., "Effect of heat treatment on corrosion behavior of AZ63 magnesium alloy in 3.5wt.\% sodium chloride solution", Corros. Sci., 111, 2016, p. 288.

19. ZHANG, X., WANG, Z. H., ZHOU, Z. H., XU, J. M., "Effects of magnetic field and rare earth addition on corrosion behavior of Al-3.0 wt\% Mg alloy, J. Alloy. Compd, 698, no. 25, 2017, p. 241.

20. FENG, Y., LEI, G., HE, Y. Q., WANG, R. C., WANG, X. F., "Discharge performance of Mg-Al$\mathrm{Pb}$-La anode for Mg-air battery", Trans. Nonferrous Met. Soc. China, 28, no. 11, 2018, p. 2274.

21. ZHU, S. J., LIU, Z. D., QU, R. X., WANG, L. G., LI, Q. K., GUAN, S. K., "Effect of rare earth and $\mathrm{Mn}$ elements on the corrosion behavior of extruded AZ61 system in $3.5 \mathrm{wt} \% \mathrm{NaCl}$ solution and salt spray test", J. Magnes. Alloy, 1, no. 3, 2013, p. 249.

22. DENG, M., WANG, R.C., FENG, Y., WANG, N. G., WANG, L.Q., "Corrosion and discharge performance of $\mathrm{Mg}-9 \% \mathrm{Al}-2.5 \% \mathrm{~Pb}$ alloy as anode for seawater activated battery", Trans. Nonferrous Met. Soc. China, 26, no. 8, 2016, p. 2144.

23. CATORCENO, L.L.C., GOMES DE ANREUA, H. F., PADILHA, A. F., "Effects of cold and warm cross-rolling on microstructure and texture evolution of AZ31B magnesium alloy sheet", $\mathrm{J}$. Magnes. Alloy, 6, no. 2, 2018, p. 121.

24. WANG, N.G., MU, Y. C., XIONG, W. H., ZHANG, J. C., LI, Q., SHI, Z.C., "Effect of crystallographic orientation on the discharge and corrosion behaviour of AP65 magnesium alloy anodes", Corros. Sci., 144, 2018, p. 107.

25. WANG, L., ZHANG, B.P., SHINOHARA, T., "Corrosion behavior of AZ91 magnesium alloy in dilute $\mathrm{NaCl}$ solutions", Mater. Des., 31, no. 2, 2010, p. 857.

Manuscript received: 28.04 .2020 